\title{
Erratum to: Malignancies after living-donor and cadaveric lung transplantations in Japanese patients
}

\author{
Satona Tanaka ${ }^{1}$ Toyofumi F. Chen-Yoshikawa ${ }^{1} \cdot$ Tetsu Yamada $^{1} \cdot$ Kyoko Hijiya $^{1}$.
}

Hideki Motoyama $^{1} \cdot$ Akihiro Aoyama $^{1} \cdot$ Hiroshi Date $^{1}$

Published online: 3 September 2016

(C) Springer Japan 2016

\section{Erratum to: Surg Today}

DOI 10.1007/s00595-016-1327-3

Unfortunately, in the original publication of the article, the follow-up period of patient 9 in Table 2 was published with an error.

The follow-up period of patient 9 should be 12 months.

The online version of the original article can be found under doi:10.1007/s00595-016-1327-3.

Hiroshi Date

hdate@kuhp.kyoto-u.ac.jp

1 Department of Thoracic Surgery, Graduate School

of Medicine, Kyoto University, 54 Shogoin-Kawahara-cho,

Sakyo-ku, Kyoto 606-8507, Japan 